\title{
DEL CRIMEN PASIONAL A LA VIOLENCIA DE GÉNERO: EVOLUCIÓN Y SU TRATAMIENTO PERIODÍSTICO
}

\author{
Rosa Rodríguez Cárcela \\ (Universidad de Sevilla) \\ rosacarcela@hotmail.com
}

\section{Resumen:}

Este artículo pretende ofrecer un análisis actual del tratamiento que los medios de comunicación ofrecen sobre la violencia de género, especialmente cuando se difunden noticias sobre asesinatos. Para ello, se hace un recorrido evolutivo sobre la utilización del término crimen pasional hasta el actual de violencia doméstica o de género. También se incluyen las expresiones que sobre este tema se utilizan habitualmente en las redacciones periodísticas, las recomendaciones de uso al respecto y una breve visión de la regulación jurídica actual de la violencia de género.

Palabras clave: Crimen pasional, violencia de género, periodismo de sucesos, homicidio, malos tratos, recomendaciones de uso.

\begin{abstract}
:
The principal aim of the present article is to give the reader an updated analysis of the characteristics of media coverage of genderbased violence issues. We are mainly interested in the diffusion of news involving tragic events -i.e. assassinations- as a result of gender violence. We start by making a survey of the terminology related to gender violence: from the definition and evolution of the term "passional crime" to the current use of the terms "domestic and gender violence". We also give insights into the phrasal expressions commonly used in the publications addressing these issues and a current juridic regulation of gender-based violence issues.
\end{abstract}

Keywords: Passional crime, gender violence, journalism of events, homicide, domestic abuse, recommendations for use.

\section{CARACTERÍSTICAS DEL CRIMEN PASIONAL}

Tal y como señala el profesor Ramón Reig, existen conflictos que entran de lleno en lo que siempre hemos conocido como periodismo de sucesos:

Acontecimientos referidos a asesinatos, maltratos, torturas, etcétera, cometidos por la gente común, cuyas actividades saltan de pronto a las páginas y espacios de los medios de comunicación (Ronda Iglesias, 2000: 11). 
Dentro de este tipo de información periodística especializada, el crimen, el asesinato, es una de las temáticas que más interés despierta tanto a nivel periodístico como social. Se trata de un hecho, que además de ser un delito genérico de homicidio, despierta alarma social por su brutal resultado, como es acabar con la vida de una o varias personas de forma violenta. Los temas sangrientos siempre han sido noticia y lo seguirán siendo.

Dentro de la temática relacionada con el crimen, el denominado no hace muchos años en los medios de comunicación como crimen pasional, es uno de los conceptos que ha experimentado una evidente evolución en su tratamiento periodístico, debido a que este tema se ha convertido en la actualidad en un problema social, jurídico y familiar de unas dimensiones que sobrepasan ampliamente la citada denominación, totalmente desfasada, anclada en el pasado y con unas connotaciones peyorativas que nada tienen que ver con un fenómeno que actualmente está considerado como violencia de género.

La realidad es que este tipo de informaciones, donde una pareja mata a otra por celos, pasiones desatadas o por posesiones enfermizas, son delitos tipificados penalmente como asesinatos. El calificativo de pasional ha sido una tradición del periodismo de sucesos, al entender que tenía unas connotaciones muy concretas, que enmascaraba lo que era el maltrato y la violencia contra la mujer.

Algunos autores han elaborado sus propias clasificaciones, en función del móvil y del tipo de víctima y del agresor que han protagonizado los hechos. En este sentido, el crimen pasional siempre ha estado ligado a una cuestión de género, puesto que se ha utilizado mayoritariamente aplicado a las relaciones sentimentales entre hombre y mujer, donde el móvil siempre se ha achacado a una causa de celos o de bajas pasiones y donde el agresor o el asesino ha sido mayoritariamente el hombre.

En este sentido, el experto en sucesos Francisco Pérez Abellán estableció en su libro Crónica de la España Negra. Los 50 crímenes más famosos la siguiente clasificación de crímenes: misteriosos, políticos, múltiples, de intriga y pasionales. El escritor y periodista describe éstos últimos:

Todos los crímenes difieren en sus detalles, sin embargo quizá es en los pasionales donde el alma humana se conmueve de forma espasmódica y se deben hacer mayores esfuerzos para comprender lo ocurrido (Pérez Abellán, 1997: 15).

Pérez Abellán matiza, no obstante, que la violencia doméstica se la ha disfrazado durante años, Ilamándola crimen pasional ${ }^{1}$. Además, según mantiene en su libro Mi marido, mi asesino, antes en los medios de comunicación se decía que los crímenes eran pasionales, pero en realidad siempre han sido el producto de los malos tratos.

Por su parte, Luis Rojas Marcos estima que las causas del crimen son múltiples y complejas, ya que intervienen condicionantes de tipo individual que predisponen a conductas aberrantes y agresivas, así como otro tipo de factores sociales, econó-

\footnotetext{
${ }^{1}$ Así lo manifiesta en una entrevista realizada en el periódico electrónico Libertad digital. www.libertad1digital.com [Consulta: 3 de noviembre de 2007].
} 
micos y culturales. Para este psiquiatra los celos, la pasión de dominio y el control son las causas que más peso ejercen en las conductas violentas de los amantes.

En el denominado crimen pasional los móviles que conducían al asesino a cometer este delito eran considerados más específicos, ya que el supuesto amor hacia otra persona podía llegar a desatar en el agresor fantasías e impulsos primitivos que desembocaban en la violencia. Esta visión poco adecuada a la realidad actual de la violencia contra la mujer ha motivado que los medios de comunicación hayan incurrido en la minimización de las agresiones a la mujer, incidiendo en la pasión amorosa como causa de las lesiones o del asesinato.

Un ejemplo de lo que se ha calificado en el pasado por los medios de comunicación como crimen pasional lo encontramos en la película Amantes, dirigida por Vicente Aranda, basada en hechos reales, donde el novio (Jorge Sanz) acaba asesinando a su novia (Maribel Verdú), incitado por los celos que tiene su amante (Victoria Abril). En este triángulo amoroso, existen los ingredientes básicos que se consideraban, tanto periodística como socialmente, que integraban el crimen pasional: celos, posesión, bajas pasiones, dominio y sentido de pertenencia.

Como la sociedad en general y los medios de comunicación en particular tienden a generalizar los hechos, muchas personas entienden que los celos son un sentimiento normal en los enamorados.

El otro factor, el ansia enfermiza de la posesión (iME PERTENECES!, ¡ME GUSTA QUE SEAS SÓLO MÍA!), también produce un fuerte impulso a entregarse ( TÓMAME, SOY TODO TUYA!, ¡ME GUSTA QUE ME DOMINES!). En opinión de Luis Rojas estos sentimientos tan negativos forman parte de la cara siniestra y sangrienta del amor:

Precisamente, éstas son las emociones que tienden a corromper y destruir el mismo amor que las hizo brotar en primer lugar. La pasión de dominio y control, justificada como un derecho natural, suele desembocar en la duda, el sentimiento de traición y en la violencia, si estos deseos no se satisfacen (Rojas Marcos, 1996: 51).

El crimen pasional contenía unas características propias que no reunían otro tipo de crímenes y así se ha estado difundiendo durante muchos años en los medios de comunicación. Un tratamiento informativo basado en una construcción social y educacional que condenaba a la mujer y justificaba, en ocasiones, a los hombres violentos. Toda una visión que tendía a culpabilizar a la víctima y eximir de responsabilidad a los homicidas y todo ello reforzado por refranes y dichos populares, claramente machistas.

Actualmente, es cada vez menos frecuente leer titulares como el publicado en el diario La Razón, del 23 de agosto de 2006, que decía: "Un pueblo roto por un crimen pasional", referido a un caso de violencia de género, con resultado de muerte por homicidio, ocurrido en Alcaudete y en el que un hombre asesinó a su novia de 19 años.

El concepto ha cambiado. No estamos ante un crimen pasional, sino ante la comisión de un grave delito, un asesinato cometido por la violencia machista de un hombre que piensa que la mujer es suya y que no puede ser de nadie más. 


\section{DENOMINACIONES PERIODÍSTICAS EMPLEADAS Y DELIMITACIÓN DEL TÉRMINO}

El término crimen pasional casi ha dejado en la práctica periodística de utilizarse. De hecho, es poco frecuente escuchar o leer esta denominación en los medios de comunicación. Lo que hace pocos años era considerado periodísticamente y socialmente un crimen pasional ha pasado mayoritariamente a denominarse con las expresiones genéricas de violencia de género o violencia doméstica. Los expertos en esta materia señalan que no es correcto considerar sinónimas ambas expresiones. Concretamente, el Centro Reina Sofía matiza que la violencia doméstica es la que ocurre exclusivamente en el ámbito doméstico, en la casa o el hogar, y se produce no sólo entre los miembros de la pareja, sino entre los hermanos o entre los padres e hijos:

De estos tipos de violencia doméstica sólo pueden conceptualizarse como violencia de género aquellos cuyas víctimas son mujeres y cuyos agresores las atacan por no adecuarse a los estereotipos socialmente construidos para ellas. Esos agresores suelen ser, principalmente, las parejas (Sanmartín, 2007: 11).

Por tanto, violencia de género es un término más amplio que incluye la violencia doméstica contra la mujer. Por género se entiende un conjunto de características que constituyen diferencias sexuales entre el hombre y la mujer. El Centro Reina Sofía entiende por violencia de género cualquier acción u omisión intencional que puede dañar a una persona, pero especifica que es un concepto que se refiere habitualmente a la violencia que afecta a la mujer (porque es la más frecuente y mayoritaria) y no a la sufrida por el hombre, puesto que es minoritaria. También establece tres tipos diferentes de violencia de género: la que se produce en las relaciones de pareja (es la más extendida en el mundo y afecta a todas las clases sociales y niveles educativos), el tráfico sexual de mujeres y la mutilación genital femenina ${ }^{2}$.

En la actualidad, los asesinatos que se cometen contra la mujer, por parte de sus maridos, esposos, cónyuges, novios, parejas, ex parejas, convivientes, amantes o conocidos tienden a difundirse en los medios de comunicación con una terminología diversa, aunque parece que el término más comúnmente empleado suele ser el de violencia de género, aunque no es una expresión unitaria. Violencia familiar, violencia contra la mujer, violencia machista, violencia sexista, violencia doméstica, crímenes de género, malos tratos, malos tratos en el ámbito doméstico, maltrato doméstico, terrorismo machista, terrorismo familiar, violencia de género con resultado de muerte o femicidios son otras expresiones utilizadas actualmente en los medios de comunicación para referirse a este tema ${ }^{3}$.

\footnotetext{
${ }^{2}$ El Centro Reina Sofía, denominación de la Fundación de la Comunidad Valenciana para el Estudio de la Violencia, es una institución que, bajo la presidencia de honor la Reina Doña Sofía, se dedica desde 1997 al análisis de la agresión a la mujer en sus distintas formas.

${ }^{3}$ Los asesinatos cometidos contra la mujer, por parte del cónyuge, pareja o novio, son denominados por el Centro Reina Sofía para el Estudio de la Violencia con el término de femicidios. El segundo informe internacional sobre los crímenes de género contra la mujer, elaborados por este organismo, distingue entre los femicidios en general, los cometidos en el ámbito doméstico y los de pareja.
} 
En este sentido, recogemos a continuación varios ejemplos de titulares de periódicos donde se utilizan diferentes términos:

- Título: "Aumenta en un 15 por ciento el número de detenidos por violencia doméstica". Subtítulo: "De enero a agosto van 5.157, 670 más que en el mismo periodo de 2002" (ABC, 20/9/2005, p. 32).

- Título: "Aumentan un $11 \%$ las denuncias por maltrato". Antetítulo: "Violencia machista. En 2005, con la Ley Integral en vigor, más mujeres han alertado de su situación" (El Correo de Andalucía, 20/9/2005, p. 6).

Se trata de la misma noticia, pero enfocada de distinta manera por estos dos diarios:

- "Violencia de género. Encarnación Rubio tenía orden de protección, pero no impidió que fuera asesinada" (El Correo de Andalucía, 27/9/2005, p. 23).

- "EI PSOE pide a la Junta que estudie la percepción juvenil de la violencia machista" (El Mundo Andalucía, 5/2/2007, p. 23).

- Título principal: "Más de 150.000 casos de violencia contra la mujer". Sumarios: "La violencia de género se ha cobrado la vida de 414 mujeres españolas entre 2001 y 2006, de las cuales 344 fueron asesinadas en el ámbito de la pareja"; "En los cuatro primeros meses de 2007 una veintena de mujeres ha muerto a consecuencia del terrorismo familiar"; "En el ámbito de la UE se calcula que han sido víctimas del maltrato doméstico el 25 por ciento de las mujeres" (La Razón, 3/5/2007, p. 29).

- "El $41 \%$ de las víctimas de malos tratos es menor de 30 años" (El Correo de Andalucía, 27/8/2007, p.17).

Como vemos, para fenómenos que a simple vista pueden parecer coincidentes se emplea un elenco de expresiones muy variadas. Sin embargo, no son sinónimas, ya que cada una de ellas tiene un matiz diferente, aunque en ocasiones el uso social, los medios de comunicación e incluso las propias normas las utilizan indistintamente.

En este sentido, cuando los medios de comunicación usan alguno de estos conceptos para referirse, por ejemplo, a un crimen, de lo que se trata específicamente es de la comisión de un delito de homicidio (Art. 138 del Código Penal) ${ }^{4}$. Las estadísticas oficiales señalan que la forma de homicidio cometida de manera más habitual hacia la mujer es el asesinato (Art. 139 del Código Penal), delito mucho más grave, ya que en el asesino concurren las circunstancias de alevosía o ensañamiento ${ }^{5}$. Por tanto, se trata de un problema social y jurídico mucho más amplio y

\footnotetext{
${ }^{4}$ Art. 138: "El que matare a otro será castigado, como reo de homicidio, con la pena de prisión de 10 a 15 años".

${ }^{5}$ Art. 139: "Será castigado con la pena de prisión de 15 a 20 años, como reo de asesinato, el que matare a otro concurriendo alguna de las circunstancias siguientes: $1^{\text {a }}$ Con alevosía. $2^{\text {a }}$ Por precio, recompensa o promesa. $3^{\text {a }}$ Con ensañamiento, aumentando deliberadamente e inhumanamente el dolor del ofendido".
} 
complejo, como es el de la violencia contra la mujer, y que engloba, además, otro tipo de delitos menos graves, pero también incluidos, como actos de violencia física y psicológica, como son las agresiones, las amenazas, las coacciones y el maltrato en general.

Según lo que hemos podido comprobar, a través de la lectura de prensa, manuales de estilo, libros, normativa, páginas web y documentos institucionales que tratan el tema de la violencia contra la mujer y los medios de comunicación, el término crimen pasional es considerado hoy en día peyorativo, incorrecto y poco adecuado para la problemática social que supone, ya que no se trata de un suceso aislado, sino inserto en un fenómeno muy extendido en la sociedad; es un conflicto jurídico y judicial y es una lacra que puede desembocar, en su más grave manifestación, en un asesinato.

Según considera el Instituto de la Mujer, dependiente del Ministerio de Trabajo y Asuntos Sociales, el término violencia doméstica hace referencia a la violencia que se ejerce contra las mujeres dentro del ámbito familiar o doméstico, por personas de su entorno como son el marido, el compañero, el padre, los hijos o los hermanos (Instituto de la Mujer, 1999: 3).

La Real Academia Española (RAE) ha recomendado el uso de la expresión violencia doméstica y no de género, y propuso al Gobierno de España, cuando se estaba tramitando el proyecto de ley contra la violencia de género en el año 2004, que se denominara Ley integral contra la violencia doméstica o por razón de sexo.

A raíz del anuncio del citado Proyecto de Ley, la Academia elaboró un informe sobre la expresión violencia de género, en el que analizaba su origen y la conveniencia de su uso en español. La RAE señala que violencia de género es una traducción del inglés gender-based violence o gender violence, difundida a partir del Congreso sobre la Mujer realizado en Pekín en 1995, y con la que se identifica la violencia, tanto física como psicológica, que se ejerce contra las mujeres por razón de su sexo, como consecuencia de su tradicional situación de sometimiento al varón en las sociedades de estructura patriarcal.

La Jefatura del Estado publicó en el Boletín Oficial del Estado (BOE) el 29 de diciembre de 2004 dicha ley, optando por la utilización del término violencia de género. Concretamente, se trata de la Ley Orgánica 1/2004, de 28 de diciembre, de Medidas de Protección Integral contra la Violencia de Género (conocida como Ley Integral). En la exposición de motivos de la citada ley, se plasma la idea que se pretende transmitir del concepto de violencia de género:

La violencia de género no es un problema que afecte al ámbito privado. Al contrario, se manifiesta como el símbolo más brutal de la desigualdad existente en nuestra sociedad. Se trata de una violencia que se dirige sobre las mujeres por el hecho mismo de serlo, por ser consideradas, por sus agresores, carentes de los derechos mínimos de libertad, respeto y capacidad de decisión [...]. Ya no es un delito invisible, sino que produce un rechazo colectivo y una evidente alarma social.

Por su parte, el artículo 1.3 de la Ley Integral contiene una definición de las conductas reprobables que integran la violencia de género: 


\section{Rosa Rodríguez Cárcela}

La violencia de género a que se refiere la presente ley comprende todo acto de violencias físicas y psicológicas, incluidas las agresiones a la libertad sexual, las amenazas, las coacciones o la privación arbitraria de libertad.

Esta opción terminológica ha resultado importante para fijar un uso común no sólo a nivel jurídico, sino también periodístico. La Academia así lo ha considerado, puesto que antes de la aprobación y entrada en vigor de esta ley estatal predominaba en los medios de comunicación españoles la denominación violencia doméstica frente a la de violencia de género. Hecho que corroboramos si tenemos en cuenta que las leyes anteriores a la Ley 1/2004 en esta materia hacían mención expresa al término violencia doméstica, lo cual tenía una repercusión directa en los medios de comunicación ${ }^{6}$.

Las juristas Paz Menéndez y Teresa Velasco consideran, partiendo de las modernas teorías sobre la importancia del género, que la violencia de género es aquella en la que el género del agresor y el de la víctima van íntimamente unidos a la explicación de dicha violencia, pues se ejerce por los hombres para mantener el control y el dominio sobre las mujeres:

Su rasgo distintivo con respecto a otras manifestaciones de la violencia es el de utilizar la diferencia sexual para transformarla en dominación social. Esta violencia puede acontecer en el ámbito doméstico (sea o no familiar en el sentido jurídico) o fuera de él (por medio de discriminaciones laborales, acoso en el trabajo, agresiones sexuales, trata de mujeres, etc.) y además de suponer un atentado contra el derecho a la dignidad, a la vida o a la integridad física de la víctima, este tipo de violencia conculca también el derecho a la igualdad (Menéndez Sebastián y Velasco Portero, 2006: 29).

En esta línea, el Instituto Andaluz de la Mujer (IAM) de la Junta de Andalucía define lo que es la violencia de género, destacando que comprende todo acto de violencia tanto física, como psicológica o sexual, incluidas las amenazas de tales actos, que se ejerce contra las mujeres. EI IAM considera que la citada LO 1/2004 introduce por primera vez la perspectiva de género como análisis del problema social e incorpora el factor cultural como causa:

Queda patente que la violencia de género que contempla y que pretende combatir esta ley es una manifestación de la discriminación, la situación de desigualdad y las relaciones de poder de los hombres sobre las mujeres (hechos que alimentan la raíz misma de la violencia de género), ejercida sobre éstas por parte de quienes sean o hayan sido sus cónyuges o de quienes estén o hayan estado ligados a ellas por relaciones similares de afectividad, aún sin convivencia.

Agrupar, por tanto, toda la problemática que afecta a la violencia contra la mujer bajo el concepto de violencia doméstica no parece ser lo más acertado, puesto que este fenómeno no se produce únicamente en el ámbito familiar o de convivencia conyugal, sino que se manifiesta también en la calle, en las agresiones a la mujer que

\footnotetext{
6 Tales como la Ley Orgánica 11/2003, de 29 de septiembre, de Medidas Concretas en Materia de Seguridad Ciudadana, Violencia Doméstica e Integración Social de los Extranjeros; o la Ley 27/2003, de 31 de julio, reguladora de la Orden de Protección de las Víctimas de la Violencia Doméstica.
} 
se cometen en la vía pública, y que aparecen reflejadas en los medios, con episodios de violencia tan trágicos como el atropellamiento de mujeres, el acuchillamiento, el asesinato a tiros o las agresiones sexuales. Todo ello es violencia contra la mujer, se produzca tanto en las casas particulares como en el ámbito público o laboral.

En esta línea se manifiesta María Isabel Menéndez Menéndez, ponente en el Congreso "Violencia y Género", que recomienda una mejor utilización del término violencia de género, que debe considerarse tanto si se produce en el ámbito público como en el privado:

Esa matización es especialmente importante porque el argumento más esgrimido para justificar la tolerancia social hacia los malos tratos a las mujeres ha sido, precisamente, que las agresiones constituían actos privados que debían resolverse dentro del hogar.

El Consejo de Europa, el Parlamento Europeo y la ONU, en sus declaraciones internacionales, utilizan la expresión la violencia contra las mujeres y las niñas, considerando Naciones Unidas que la violencia doméstica es un caso de violencia con base en el género ${ }^{7}$.

En opinión de la autora de este artículo, la expresión más correcta y directa que debe emplearse en los medios de comunicación para referirse genéricamente a este problema es el de violencia contra la mujer, especificando a continuación el tipo de falta o delito cometido. De hecho, los juzgados españoles que sentencian actualmente sobre esta materia se denominan Juzgados de Violencia sobre la Mujer (JVM). El tipo de delitos que instruyen son lesiones contra la libertad, contra la libertad e indemnidad sexual, contra la integridad moral, contra los derechos y deberes familiares, los homicidios y otros.

Todos estos delitos son los que integran la violencia contra la mujer y que aparecen reflejados en los medios. Según los datos facilitados por el Consejo General del Poder Judicial (CJPJ) ${ }^{8}$, el tipo de delito que se instruye con mayor frecuencia en los JVM son las lesiones (un 69\%), seguido de otros delitos (11\%) y los relacionados contra la libertad (un $9 \%)^{9}$. Por el contrario, los que se instruyen en menor número son los homicidios (un $0,1 \%$ ), contra la libertad e indemnidad sexual $(1 \%)^{10}$ y contra los derechos y deberes familiares (un $4 \%)^{11}$. Hay que aclarar que en los delitos de

\footnotetext{
7 Así se recogen en recomendaciones y resoluciones comunitarias, así como en la IV Conferencia Mundial sobre Mujeres, celebrada en Pekín, en 1995.

8 Datos de denuncias y procedimientos penales y civiles registrados y órdenes de protección solicitadas en los Juzgados de Violencia sobre la Mujer (JVM) en el segundo trimestre del año 2007. Consejo General del Poder Judicial y Observatorio contra la Violencia Doméstica y de Género.

${ }^{9}$ Recogidos en el Título VI del Código Penal y que engloban delitos referidos a las detenciones ilegales y secuestros, las amenazas y las coacciones.

10 Recogidos en el Título VIII del Código Penal y que se refiere a delitos como las agresiones sexuales, los abusos sexuales, el acoso sexual, el exhibicionismo y la provocación sexual, la prostitución y la corrupción de menores.
} 
homicidios se incluyen tanto los consumados como los intentados (tentativas de homicidio), por lo que su número no es el mismo que el de mujeres muertas a manos de su pareja o ex pareja.

\section{VIOLENCIA DE GÉNERO Y REGULACIÓN JURÍDICA}

La respuesta jurídica a este tipo de violencia está sustentada en valores y principios recogidos en la Constitución Española de 1978, como son la dignidad de la persona (Art. 10), el derecho a la igualad (Art. 14), el derecho a la vida y a la integridad física y moral (Art. 15), el derecho del hombre y la mujer a contraer matrimonio en plena igualdad jurídica (Art. 32) o la protección social, económica y jurídica de la familia (Art. 39).

El Código Penal regula en su artículo 173 la violencia doméstica, que se engloba dentro de los delitos contra la integridad moral; también se recoge en el artículo 153, referido a los malos tratos en el ámbito doméstico (encuadrado en el Título III del Libro II, de las lesiones) y en el 617 como falta; y en el artículo 39, el delito de asesinato, como manifestación más extrema de esta violencia. Curiosamente, se observa que tanto los medios escritos como los audiovisuales continúan utilizando el término parricidio cuando informan sobre un suceso relacionado con el asesinato del cónyuge, ascendientes o descendientes. Sin embargo, este delito, junto con el infanticidio, fueron suprimidos por el actual Código Penal, en vigor desde 1995, y son sancionados como homicidio o asesinato.

Ilustramos con un ejemplo esta incorrecta utilización del delito, ya derogado, de parricidio, aplicado a la violencia de género:

- Título: "El parricida de Villegas ingresa en la cárcel". Antetítulo: "El anciano confiesa que mató a su mujer 'por pena' y para evitar más cargas a su hijo" (El Correo de Andalucía, 27/9/2005, p. 1).

La violencia de género es, como ya se ha comentado, jurídica y socialmente un concepto más amplio que contempla todos aquellos delitos que se cometen contra la mujer y están relacionados con actos de violencia física, psicológica y sexual. Los homicidios en la pareja, antes llamados crímenes pasionales, también se encuadran actualmente como la más grave manifestación de la violencia de género y son conductas delictivas tipificadas en el Código Penal como un delito de homicidio en cualquiera de sus formas (Artículos 138 al 143, que incluyen el homicidio, el asesinato, el homicidio imprudente y la inducción al suicidio)

Dentro de los delitos genéricos de lesiones (Título III del Código Penal), que hemos comprobado que son los que con más frecuencia se instruyen en los Juzgados de Violencia sobre la Mujer, el que recoge una de las formas específicas de vilencia de género es el Artículo 153, referido a los malos tratos ${ }^{12}$.

\footnotetext{
${ }^{11}$ Recogidos en el Capítulo III, del Título XII del Código Penal (Delitos contra las relaciones familiares) y referidos al quebrantamiento de los deberes de custodia y de la inducción de menores al abandono de domicilio, de la sustracción de menores; y del abandono de familia, menores e incapaces.

12 Redacción según reforma introducida en el Código Penal por la LO 1/2004, de 28 de diciembre.
} 
La profesora de Derecho de la Universidad de Granada, Ana Rubio, explica la diferencia existente entre los Artículos 153 y 173.2 del Código Penal y defiende la importancia de los dos como un instrumento adecuado para enfrentarse a la violencia específica que es la violencia de género en el ámbito doméstico:

La violencia de género en el Código Penal se castiga, por un lado, en el Artículo 153 cuando se vulnera la integridad física y psíquica o incluso cuando se pone en peligro, como sería el supuesto de amenazas leves, y, por otro, en el Artículo 173.2 cuando lo que se vulnera es la integridad moral. Lo relevante en ambos preceptos es que se destacan las relaciones que vinculan al agresor con su víctima, más que el hecho de que dichas conductas se produzcan en el hogar familiar (Rubio, 2004: $50)$.

Las complejas realidades que se manifiestan a través de la violencia de género maltrato inicial, asesinato posterior o numerosas conductas punibles que establece el Código Penal- indican que se trata de una forma de criminalidad que supone una grave problemática. Este tipo de violencia incluye delitos que van desde las amenazas, pasando por los malos tratos, psíquicos y físicos, hasta llegar a las lesiones y los homicidios como formas más extremas.

En este sentido, como complemento al Código Penal, en los últimos años se han producido avances legislativos en la lucha contra la violencia de género, como son los juicios rápidos, las órdenes de protección o la creación de los Juzgados de Violencia sobre la Mujer. La legislación española en esta materia se ha ido modificando en un intento de frenar el alarmante drama que viven muchas mujeres que sufren todo tipo de violencia por el hecho de serlo.

Concretamente, en el derecho español se encuentran, entre otras, la Ley Orgánica 11/2003, de 29 de septiembre, de Medidas Concretas en Materia de Seguridad Ciudadana, Violencia Doméstica e Integración Social de los Extranjeros; la Ley Orgánica 15/2003, de 25 de noviembre, por la que se modifica la Ley Orgánica 10/1995, de 23 de noviembre, del Código Penal; la Ley 27/2003, de 31 de julio, reguladora de la Orden de Protección de las Víctimas de la Violencia Doméstica y que añade el Art. 544 en la Ley de Enjuiciamiento Criminal (LECr); o el Real Decreto 355/2004, de 5 de marzo, ordenador del registro central para la protección de las víctimas de violencia doméstica ${ }^{13}$.

Junto a esta normativa estatal, se citan también leyes aprobadas por las comunidades autónomas, dentro de su ámbito competencial. El Parlamento de Andalucía aprobó el 14 de noviembre de 2007 la Ley de Medidas de Prevención y Protección Integral contra la Violencia de Género (un título casi idéntico a la Ley Orgánica es-

\footnotetext{
13 EI RD 355/2004 incorpora en el ordenamiento jurídico un nuevo instrumento de protección (tanto de amparo como de tutela) frente a las infracciones penales cometidas exclusivamente en el entorno familiar. Concretamente, según recoge el Artículo 2, dicho registro es un sistema de información sobre penas y medidas de seguridad, impuestas a los cónyuges o convivientes maltratadores u homicidas, por delitos o faltas y medidas cautelares, así como órdenes de protección acordadas en procedimientos penales en tramitación. El desarrollo completo de esta normativa está publicado en el BOE núm. 73, de 25 de marzo de 2004.
} 


\section{Rosa Rodríguez Cárcela}

tatal de 2004). En dicha Ley se garantiza la personación de la Junta en juicios sobre casos de muerte violenta. Resulta llamativa la utilización del término muerte violenta, cuando de lo que se trata en realidad es de un delito de homicidio.

Por su parte, el artículo 16 del Estatuto de Autonomía de Andalucía establece que las mujeres tienen derecho a una protección integral contra la violencia de género, que incluirá medidas preventivas, asistenciales y otras ayudas.

De toda la regulación jurídica creada por el derecho español en esta materia cabe destacar especialmente la aprobación de la Ley Orgánica 1/2004, de 28 de diciembre, de Medidas de Protección Integral contra la Violencia de Género (LOIVG), que regula medidas de sensibilización, prevención y detección en los ámbitos educativos, de la publicidad y de los medios de comunicación y sanitario.

Además, gracias a esta ley, se crean los Juzgados de Violencia sobre la Mujer que, hasta la fecha, no existían en España, y que están encargados de instruir las denuncias y procedimientos relacionados con este tipo de violencia. Se trata de la mayor innovación, en el ámbito procesal, de esta ley. Concretamente, el Artículo 44 concreta las competencias de los JVM en materia civil y penal ${ }^{14}$. En este sentido, se produce la pérdida de competencia objetiva de los tribunales civiles cuando se produzcan actos de violencia contra la mujer, ya que el juez civil deberá inhibirse al juez de violencia sobre la mujer. También se crea la figura del fiscal contra la violencia sobre la mujer (Art. 70), a quien se encomienda la supervisión y coordinación de las actuaciones en materia de violencia de género.

En opinión de la profesora de Derecho Penal de la Universidad de Sevilla, Antonia Monge Fernández, la citada Ley Orgánica contempla como violencia de género:

Los delitos que se perpetren contra la mujer; es decir, el sujeto pasivo es el que da entidad a esta denominación, con independencia del resultado, que puede ser de muerte o no. No se contempla, por tanto, un delito específico ${ }^{15}$.

Por otro lado, tal y como señala el Instituto Andaluz de la Mujer, la violencia de género, debido al rechazo colectivo y a la evidente alarma social que produce, ya no está considerado como un delito o delitos invisibles, sino que despierta el interés público y son conductas delictivas contra la mujer perseguibles de oficio.

\footnotetext{
14 Es el Art. 41.1.a) el que dispone específicamente las competencias de estos juzgados para instruir juicios que exijan responsabilidades penales por delitos cometidos contra la mujer relativos a homicidio, aborto, lesiones, lesiones al feto, delitos contra la libertad e indemnidad sexuales o cualquier otro delito cometido con violencia e intimidación, siempre que se hubiesen cometido contra quien sea o haya sido su esposa, o mujer que esté o haya estado ligada al autor por análoga relación de afectividad, aún sin convivencia, así como de los cometidos sobre los descendientes, propios o de la esposa o conviviente, o sobre los menores o incapaces que con él convivan o que se hallen sujetos a la potestad, tutela, curatela, acogimiento o guarda de hecho de la esposa o conviviente, cuando también se haya producido un acto de violencia de género".
}

15 Declaraciones hechas a la autora de este artículo el 11 de diciembre de 2007. 
No obstante, algunos juristas -pese a reconocer que la LOIVG ofrece una respuesta integral a un tipo concreto de violencia de género, como es la de la pareja en la que la víctima es una mujer-, han detectado algunas limitaciones, ya que entienden que no incluye todas las manifestaciones de la violencia de género:

La fórmula legal deja fuera, en primer término, la violencia ejercida sobre las mujeres como manifestación de relaciones de poder por varones con los que no tienen lazos familiares o domésticos (caso de la violencia en el trabajo) y, en segundo lugar, la practicada por quienes teniendo con la mujer un vínculo familiar, éste no es el propio de la relación de pareja, como ocurre con el padre o los hermanos [...]. Aunque más excepcionales, también quedan fuera de la ley aquellos supuestos en los que se produzca una agresión de la mujer al varón (Menéndez y Velasco, 2006).

El Consejo General del Poder Judicial (CGPJ) también expresa que existen otras manifestaciones de la violencia de género, que no sólo se producen en las relaciones afectivas y que no están incluidas en la Ley Integral, como es el caso de los ámbitos laboral y social, a través de las figuras de los acosos sexuales y por razón de sexo. Por este motivo, concluye que no existe en la legislación española un plan realmente universal que enfoque jurídico-penalmente la violencia de género ${ }^{16}$.

Ante estas afirmaciones, hay que recordar que en el apartado anterior se indicó que los expertos en la materia señalaban que la violencia de género se entiende actualmente como un fenómeno donde la víctima es la mujer, puesto que los casos de agresiones al hombre son minoritarios. Por tanto, el concepto está actualmente asimilado exclusivamente a la mujer. También se ha apuntado, tomando las referencias del Centro Reina Sofía, que la violencia doméstica que se ejerce contra la mujer en su casa u hogar y es ejecutada por sus parejas se engloba dentro de la violencia de género, pero no estaría conceptualizada como tal la violencia doméstica que ocurre entre los hermanos o entre los padres e hijos. Como vemos, tanto desde el punto de vista técnico, como jurídico, social o lingüístico se trata de un tema complejo, abierto a interpretaciones y visiones diversas.

La legislación, en definitiva, ha introducido cambios importantes para atajar este problema, pero los hechos diarios ponen de manifiesto que no es suficiente. La violencia de género necesita de otro tipo de medidas añadidas que prevengan y ayuden a eliminar estos comportamientos violentos contra la mujer, donde los medios de comunicación también juegan un importante papel. El jurista David Lorenzo Morillas Fernández opina al respecto que el fenómeno global de este tipo de violencia requiere de actuaciones de todo tipo:

Sociales, preventivas, económicas, jurídico-administrativas, civiles, etc. Medidas encaminadas a actuar como modelos previos a la intervención penal, que ha de estar basada en los presupuestos básicos del principio de intervención mínima (Morillas Fernández, 2003: 23).

\footnotetext{
16 Conclusiones aprobadas en el curso de formación continua del CGPJ "La valoración del daño en las víctimas de violencia de género", celebrado los días 10, 11 y 12 de septiembre de 2007.
} 


\section{RECOMENDACIONES DE USO}

Una de las críticas más extendidas que el Instituto de la Mujer ha realizado en los últimos años sobre el tratamiento que los medios de comunicación hacen de la violencia contra las mujeres es que suelen justificar las conductas de los agresores; es decir, encuentran alguna razón que justifica la conducta violenta o minimizan la culpa del presunto asesino o maltratador.

La crítica hacia los medios de comunicación, tanto de las instituciones públicas como de los expertos en esta materia, suele estar fundada en que las informaciones que se difunden tienden a utilizar prejuicios y valoraciones, presentando estos sucesos de violencia de género como hechos aislados y no como parte de una violencia generalizada y aceptada por la propia sociedad.

No obstante, también hay que reconocer que los medios de comunicación actualmente están cambiando el tratamiento informativo que conceden a la violencia de género y cada vez dedican más espacio a este tema, que antes era relegado a un sitio reducido o marginal. En los últimos años se observa una mayor toma de conciencia sobre este grave problema que, lamentablemente, sigue siendo noticia casi a diario en los medios. Pero todavía queda mucho camino por hacer y mejorar en las redacciones y empresas periodísticas sobre este asunto, especialmente a la hora de explicar las causas de la violencia producida, el móvil que provoca un asesinato y el excesivo empleo de las fuentes secundarias que se difunden (sobre todo las vecinales, llenas de suposiciones y tópicos), con el fin de evitar la manida utilización de afirmaciones del acervo popular que nada aportan a la calidad de la información que se difunde, pero sí contribuyen gravemente a sustentar estereotipos y prejuicios existentes.

Como muestra, reseñamos varios párrafos de una información de $A B C$ (27/08/2007, p. 44), titulada "Dos mujeres más asesinadas por sus parejas, ambas a cuchilladas", donde se elabora la noticia exclusivamente con fuentes vecinales:

Los hechos ocurrieron en el apartamento en el que ambos residían desde hace unos ocho meses y, según han manifestado algunos vecinos de la pareja, el hombre parecía tener alguna enfermedad mental [...]. Ana Kuropatkin, una vecina de la pareja, aseguró que la joven y su esposo formaban 'una familia bien avenida' y añadió que nunca escuchó pelear al matrimonio [...] Ana explicó que, por lo que había hablado con la pareja, eran de origen humilde, 'pero vivían bien y no parecía que tuvieran problemas'.

Las agresiones, el maltrato y el asesinato de la mujer nunca deben minimizarse en las informaciones, ni incurrir en la mal llamada pasión amorosa como causa de la violencia cometida o caer en expresiones como podría tener un móvil pasional para explicar una noticia sobre un asesinato cometido contra una mujer.

Veamos otro ejemplo, donde se refleja el uso inapropiado del móvil pasional:

- Título: "El drama de un inmigrante". Subtítulo: "Vecinos de El Saucejo recogen firmas a favor del autor de la muerte de su esposa". Se trata de una crónica publicada por El Correo de Andalucía, el 13 de agosto de 1995, donde se infor- 
maba que Ana Díaz había sido asesinada por su marido en el domicilio conyugal, al día siguiente de regresar éste de Alemania. En el desarrollo del texto hay un ladillo titulado: "Ataque de celos" y a continuación indica el periodista:

Al día siguiente de su llegada sobre las seis de la tarde, Juan salió del domicilio conyugal, avisó a uno de sus vecinos de que había estrangulado a su esposa y esperó a que llegaran la Guardia Civil y la Policía Local. Parece ser que, en su declaración, Juan dijo que había sorprendido a su mujer hablando por teléfono con un hombre, lo que hace pensar en un crimen pasional.

El Instituto Andaluz de la Mujer dispone de un manual de estilo, donde se ofrecen interesantes consejos a los periodistas que hacen información de sucesos, de tribunales o tratan noticias sobre violencia. Entre otros, se indican:

1. No minimizar las agresiones e incidencia en la mal llamada pasión amorosa como causa de las lesiones.

2. Explicar los motivos exactos de las causas de las agresiones.

3. Evitar la difusión de estereotipos y prejuicios que justifican las agresiones y normalizan el comportamiento violento masculino.

4. Evitar la utilización de tópicos y afirmaciones del acervo popular.

5. No presentar la agresión como un hecho aislado, como si fuera una consecuencia lógica de la pasión amorosa de algunos sujetos.

El documento "Mujer, Violencia y Medios de Comunicación", elaborado conjuntamente entre técnicos del Instituto de la Mujer y profesionales de RTVE en el año 2002, establece un denominado manual de urgencia, con unos principios que deben tener en cuenta los profesionales de los medios al difundir noticias de violencia de género ${ }^{17}$. Entre los más destacados, podemos citar los siguientes:

1. Evitar los modelos de mujer que lesionen su dignidad.

2. Los malos tratos contra las mujeres atentan contra los derechos humanos.

3. No confundir el morbo con el interés social.

4. No todas las fuentes informativas son fiables.

5. Dar información útil y asesorarse previamente.

6. Identificar la figura del agresor, respetar la dignidad de la víctima.

7. La imagen no lo es todo, no caer en el amarillismo.

17 Se trata de un documento resultado de un trabajo de investigación, análisis y debate donde participaron decenas de personas expertas en violencia contra la mujer, así como medios de comunicación. 
8. Las cifras pueden referirse a distintas realidades: informarse y explicar.

9. Los estereotipos y los tópicos frivolizan y banalizan.

Especialmente importante es la recomendación que señala que el agresor debe ser identificado claramente, si no con su identidad, dadas las cautelas judiciales, sí en cuanto a su comportamiento, su forma de vida o sus antecedentes penales (caso de tenerlos). Tampoco se debe minimizar en los medios los actos delictivos cometidos por los autores de un asesinato, utilizando expresiones eufemísticas como el agresor o el maltratador; en realidad son delincuentes, homicidas, asesinos, criminales. Siempre teniendo presente, como medida cautelar de los periodistas, que si todavía no ha sido juzgado y sentenciado el responsable del delito, se debe anteponer la palabra presunto.

En definitiva, de lo que se trata es de ayudar a las mujeres en particular y a la sociedad en general a identificar la figura del maltratador, del agresor o del asesino. En este sentido, añade la periodista Pilar López Díez, especializada en violencia ejercida contra las mujeres, que existe en los medios poco interés por conocer el modo de vida del agresor y se desconoce la profesión de la mayoría de ellos:

Cuando se trata de explicar el porqué de la acción violenta, se recurre al estereotipo como el argumento más simple (alcoholismo, celos, crimen pasional, estrés, problemas psicológicos, delincuencia y otros) ${ }^{18}$.

También hay que tener muy en cuenta el principio que establece evitar los estereotipos, prestando atención a la utilización de ciertos adjetivos, frases hechas y tópicos que frivolizan o minimizan la noticia. Calificativos atribuidos al asesino como celoso, bebedor, era una persona normal o no sabía lo que hacía porque tenía una enfermedad mental, así como frases destinadas a la mujer asesinada como salía con amigas o tenía un amante desvían la atención de las verdaderas causas de la tragedia y provocan una imagen distorsionada.

La siguiente noticia publicada por El Mundo ejemplifica cómo en ocasiones ciertas declaraciones a favor del autor del delito no ayudan a clarificar los hechos, sino que distorsionan los mismos:

- Título: "Un hombre mata de 56 puñaladas a su pareja en Aranjuez". Último párrafo de la información: "Muchos en Aranjuez sabían que Paquito era esquizofrénico aunque no violento, según cuenta un amigo. 'Yo diría que era impulsivo, pero no agresivo', dijo uno de sus compañeros" (El Mundo, 16/6/2007, p. 27).

El citado documento elaborado por la RTVE incide, en cuanto al tratamiento informativo que deben ofrecer los medios, que las mujeres que padecen este tipo de violencia presentan un perfil que no se corresponde con el de las víctimas de un suceso aislado. Por este motivo, aconseja lo siguiente:

\footnotetext{
18 Ponencia La violencia contra las mujeres en los medios de comunicación, publicada en el documento
} "Mujer, Violencia y Medios de Comunicación". 
Los malos tratos son un delito cuyo origen está en la consideración de inferioridad de las mujeres, y no se puede presentar como un crimen pasional. Por tanto, las noticias referidas a violencia contra las mujeres deben ubicarse en las secciones de sociedad, y nunca como sucesos. [...] Un caso de violencia de género a continuación de una noticia sobre un ajuste de cuentas entre bandas, por ejemplo, un incendio o un accidente, induce a una lectura muy diferente a la pedagogía social que se pretende. Se trataría, entonces, de un suceso aislado o fortuito y no de un problema de profundas raíces sociales (RTVE, 2002: 11).

En esta línea, los directores de medios de comunicación de Baleares suscribieron en el año 2004 un acuerdo, acordado por el Instituto de la Mujer y el Sindicato de Periodistas, comprometiéndose a seguir un protocolo en el tratamiento de las informaciones sobre la violencia de género. Entre sus compromisos se incluye, entre otras recomendaciones, no presentar los casos de violencia contra la mujer como situaciones aisladas, y dejar de tratar con ambigüedad y/o neutralidad estos casos.

La información de la edición digital de El Mundo que recoge esta noticia, señala que la representante del Sindicato de Periodistas de Baleares (SPIB), Marisa Goñi, advirtió de la importancia de los términos empleados en las informaciones redactadas al respecto, cuestionando los motivos por los cuales en algunas ocasiones todavía se utiliza la expresión crimen pasional, algo que no ocurre en las noticias sobre atentados terroristas a los que nadie se refiere como crimen ideológico ${ }^{19}$.

De nuevo, la doctora en Ciencias de la Información Pilar López, en las I Jornadas sobre Mujeres, violencia de género y medios de comunicación, celebradas en Almería en 2006, ha criticado el tratamiento periodístico que reciben los casos de malos tratos. Su recomendación es evitar los estereotipos sexistas que aún conviven en las redacciones de periódicos, radios y televisiones. Asimismo, apunta al compromiso diario que tienen los profesionales de los medios de comunicación a la hora de informar y concienciar a la sociedad. En concreto, señala que uno de los usos más frecuentes realizados por los medios es identificar a las víctimas de esta violencia antes que a los agresores (la costumbre de invisibilizar al agresor) ${ }^{20}$.

El grupo RTVE ha elaborado el documento "Representación de la violencia de género en los informativos de TVE", que está conformado como un manual de urgencia en el tratamiento informativo de la violencia masculina contra mas mujeres ${ }^{21}$. De las trece conclusiones que incluye el citado manual, destacamos algunas de ellas:

\footnotetext{
19 "Los medios de Baleares firman un protocolo para tratar las noticias sobre violencia doméstica". Disponible en www.elmundo.es/elmundo/2004/03/03/comunicacion/1078324544.html

20 "Las periodistas critican el tratamiento de la violencia machista". Disponible en http://www.elpais.com/articulo/andalucia/periodistas/critican/tratamiento/violencia/machista/elpepuespan d/20061129elpand_13/Tes

21 Este documento, dirigido por Pilar López Díez, ha sido editado por el Instituto Oficial de Radio y Televisión (RTVE, 2006). El equipo colaborador ha estado integrado por Elvira Altés (Universidad Autónoma de Barcelona), Felicidad Loscertales (Universidad de Sevilla), Ma José Gámez (Universidad Jaime I de Castellón) y Sonia Núñez (Universidad Rey Juan Carlos, Madrid). La metodología de este estudio ha estado basado en el análisis de 71 noticias emitidas por los tres telediarios de TVE y consideradas como violencia de género.
} 
1. La violencia masculina contra las mujeres es un delito que atenta contra los derechos humanos.

2. Facilitar información útil y necesaria (contar a la audiencia las razones de la existencia del problema).

3. El agresor y la víctima (debe tenerse cuidado con la identificación del domicilio de la mujer asesinada a través de las imágenes. En el caso de los agresores, cuando han sido condenados, hay situaciones -en el caso de los violadores- en donde sí son identificados, y otros, en el caso de asesinos o maltratadotes, en donde se protege su identidad. Hay algunas situaciones en donde el redactor toma la iniciativa de identificar con nombre y apellidos al agresor, porque éste se ha inculpado ante la policía; es una práctica de debe extenderse).

4. Atención a las cifras (especialmente se echa en falta el tratamiento informativo de casos de acoso sexual en el ámbito laboral que ayudaría a visibilizar un grave problema que está afectando a muchas mujeres, especialmente a las jóvenes que acceden al mercado de trabajo y que no se atreven a denunciar).

5. El problema de los estereotipos (como son utilizar el crimen pasional como motivo de la violencia; o las drogas y el alcohol, circunstancias que deberían evitarse y sustituirse. Sería recomendable evitar la alusión a las discusiones, ya que inducen a explicar la violencia como la consecuencia lógica de la situación de deterioro).

6. Lenguaje textual (reflexionar sobre la abundante utilización del vocablo hombre para referirse a una persona del sexo masculino que mata o asesina a una mujer y sobre la escasez de términos como homicida, agresor, malhechor, delincuente, asesino, etc.).

7. La atención a la audiencia masculina (es preciso que los medios de comunicación, especialmente en los informativos, pero también en los programas de actualidad y debate, empiecen a visibilizar el rechazo de la parte masculina de la población que no comparte las estrategias de dominación y control de los maltratadores).

La LO 1/2004, de Medidas de Protección Integral contra la Violencia de Género, dedica específicamente el capítulo II al ámbito de la publicidad y de los medios de comunicación. En concreto, los artículos 13 y 14 hacen dos recomendaciones importantes a los medios. Una, que no difundan informaciones que favorezcan situaciones de desigualdad de las mujeres. La segunda, que se garantice en las noticias sobre esta temática la dignidad de las mujeres, sobre todo en el tratamiento gráfico.

La Vicepresidencia del Gobierno de España también ha establecido en 2007 acuerdos de colaboración con las cadenas de televisión públicas y privadas, con vistas a difundir un mejor tratamiento informativo en las noticias de violencia de género. Dichas medidas consisten fundamentalmente en la mención del teléfono 016 en toda información sobre este tema, la contextualización de estas noticias en el marco de la lucha contra este hecho social, la difusión de las sentencias de los maltratadores o los homicidas, la constitución de un grupo de expertos para analizar el tratamiento informativo que debe darse a la violencia de género y una corriente a favor de la igualdad y el cambio social que debe inspirar todos los contenidos informativos. 


\section{REFERENCIAS BIBLIOGRÁFICAS}

MENÉNDEZ SEBASTIÁN, P.; VELASCO PORTERO, T. La incidencia de la violencia de género en el contrato de trabajo. Madrid: Ediciones Cinca, 2006.

MORILLAS FERNÁNDEZ, D. L. Análisis criminológico del delito de violencia doméstica. Cádiz: Universidad de Cádiz, 2003.

PÉREZ ABELLÁN, F. Crónica de la España Negra. Los 50 crímenes más famosos. Madrid: Espasa-Calpe, 1997.

ROJAS MARCOS, L. Las semillas de la violencia. Madrid: Espasa-Calpe, 1995.

RONDA IGLESIAS, J.; CALERO MARTíNEZ, J. M. (2000): Manual de Periodismo Judicial. Sevilla: Universidad de Sevilla, 2000.

RUBIO, A. Análisis jurídico de la violencia contra las mujeres. Sevilla: Instituto Andaluz de la Mujer, 2004.

SANMARTíN, J. II Informe Internacional. Violencia contra la mujer en las relaciones de pareja (estadísticas y legislación). Valencia: Centro Reina Sofía, 2007.

\section{Breve semblanza de la autora}

Rosa María Rodríguez Cárcela es periodista y licenciada en Derecho por la Universidad de Sevilla. Desde el año 2000 pertenece al Grupo de Investigación en Estructura, Historia y Contenidos de la Comunicación de la Universidad de Sevilla. Ha colaborado en $A B C$ de Sevilla y Diario de Sevilla. También ha realizado labores docentes, impartiendo clases de "Comunicación empresarial" en diversas entidades; además de coordinar las jornadas sobre "Periodismo judicial" (Universidad de Sevilla, 2004) y "Libertad de expresión y sus límites" (APC-Universidad de Sevilla, 2003) 